\title{
Implantable Loop Recorder in Clinical Practice
}

\author{
Dominique Babuty, Bertrand Pierre, Nicolas Clémenty, \\ Bénédicte Lallemand, Olivier Marie and Laurent Fauchier \\ François Rabelais University / Hospital Trousseau Tours
}

France

\section{Introduction}

Implantable Loop Recorder (ILR) or Insertable Cardiac Monitor (ICM) is a tool developed in the 1990's which allows permanent monitoring of cardiac rhythm during a period exceeding one year. The major interest of this new tool is to establish a closed correlation between symptoms and heart rhythm. The first application of ICM was the diagnosis of recurrent syncope. Syncope is a common disorder which may recur and impair the survival and the quality of life of the patients. The objective of the investigation of syncope is to diagnose the cardiac aetiology because the mortality in this case is high. About half of the patients implanted with an ICM complains of a new syncope and about $50 \%$ of these patients had documented cardiac rhythm disturbances. The most frequent is a sinus bradycardia or sinus arrest but these results depend on the age of patients, resting ECG abnormalities and structural cardiac disease. A classification of the mechanisms of recurrent syncopes has been defined with the results of the ISSUE study separating the syncope due to primary cardiac arrhythmia from neurally-mediated syncope and from unknown syncope. The analysis of the presyncopal phase on the ICM restored ECG allows physicians to adapt the treatment (antiarrhythmic (with $2 \mathrm{~h}$ ) agents or pacemaker) and optimize the programming of the pacemaker when necessary. It is recommended to implant the ICM early in the syncope patients with a normal physical examination, normal ECG and without structural heart disease and negative tilt testing. In the presence of cardiac disease, it is recommended to implant the ICM after performing an electrophysiological study and tilt testing. In syncope patients with depressed left ventricular ejection fraction, the implantation of an automatic implantable cardiac defibrillator is preferable. Early application of an ICM reduces the cost of the investigation of the patients suffering from syncope, especially when the electrophysiological study is avoided. The indications of the ICM tend to be extended to new syncope populations such as pediatric patients, the epileptic population and older patients suffering from unexplained falls. New algorithms are developed by the manufacturers which allow a good analysis of electrical atrial activity and open new applications of the ICM in the managements of patients treated for atrial arrhythmias.

\section{Syncopes and unexplained recurrent syncopes}

Syncope is a common disorder with an annual incidence of 1.3-2.7 episodes/1000 per year. Recurrent syncopes are also frequent, accounting for $3 \%$ of emergency visits and $1 \%$ of 
hospital admissions in the US. The diagnosis of cardiac syncope remains the principal objective in these patients because the mortality rates exceed $30 \%$ in this subgroup of patients (Kapoor et al., 1983; Soteriades et al., 2002). However, their diagnosis is often difficult, leading to repetitive hospitalizations and clinical investigations. About $40 \%$ of diagnoses are established after the related history is considered and a meticulous physical examination and resting ECG recorded, but in $60 \%$ the diagnosis is probable or uncertain. The applications of the laboratory investigations are limited. The ambulatory ECG of 24 or 48 hours identified a rhythmic aetiology in 19\% of cases; the electrophysiological study is only useful in patients with underlying structural cardiac disease or resting ECG abnormalities (Task force 2004; Strickberer et al., 2006). Tilt table testing is useful to provoke neurally-mediated syncope, but its specificity and sensitivity are still debated (Moya et al., 2001). Exercise stress testing is not recommended except in stress induced syncope. Neurological testings are also not recommended (Task force 2004; Moya et al., 2009). Since clear recommendations published in 2004 and 2009 about the diagnosis strategy of syncope a median of 13 performed tests per patient has been reported in a recent large prospective study before considering ICM implantation (Edvardsson et al., 2011).

After complete investigations, recurrent syncopes remain undiagnosed in about $20-30 \%$ (Krahn et al., 1999a; Brignole et al., 2005a; Vitale et al., 2010). The gold standard for the diagnosis of an arrhythmic event is the ECG recording during a syncopal episode which can be obtained by a prolonged ECG recording. The first developed method was the external loop recorder but patient compliance is low and the duration is limited to a few weeks. About $20 \%$ of the patients failed to activate their loop recorder properly, resulting in an undiagnosed test (Sivakumaran et al., 2003). The second method is the implantable loop recorder which now allows for a monitoring of cardiac rhythm over three years. This method of investigation for recurrent syncope is recommended by the Task force (Task force, 2004; Moya et al., 2009). A recent study estimated that ICM should be implanted in two thirds of the patients suffering from unexplained recurrent syncopes (Vitale et al., 2010) but only $18 \%$ of these patients were implanted. Although the ICM has been recognized as a useful tool in the diagnosis of recurrent syncopes in the latest guidelines for the management of recurrent syncope it is always underutilized.

\section{Methods}

\subsection{Principle}

We describe for example the first device manufactured for the market. It is a small $(62 \times 19 \times 8$ $\mathrm{mm}$ ) titanium box of $9 \mathrm{~cm}^{3}$ in volume and weighing $17 \mathrm{~g}$. The ICM is a single-lead ECG recording device with an initial battery life of 14 months (Reveal ${ }^{\circledR}$ 9525, 9526 Medtronic USA, Minneapolis) and which is now 36 months (Reveal® DX 9528 Medtronic USA, Minneapolis). The two sensing bipoles are separated by a distance of $37 \mathrm{~mm}$. For the most recent device the bipolar electrocardiogram signal is stored in a circular memory of 49.5 minutes. After spontaneous symptoms, the memory is frozen with a patient assistant: 6.5 minutes of the preceding ECG signal are stored and 1 minute after activation. Three spontaneous episodes can be stored. The rhythmic events can be automatically stored in accordance with the alert programmed limits (27 episodes -0.5 minutes pre and 0.5 minutes post-activation). The ECG can be retrieved by a standard programmer (Medtronic 2090, Medtronic USA, Minneapolis) (figure 1). New detection algorithms proved their efficiency to detect the presence of atrial arrhythmias (Reveal ${ }^{\circledR}$ XT, Medtronic USA, Minneapolis) 
(Hindricks et al., 2010) and will participate in the extension of the indications of the ICM implantation to patients suffering from palpitations, atrial fibrillation etc...

Others devices (Paruchuri et al., 2011) are in development by others manufacturers (Confirm ILR, St Jude Medical and Sleuth ILR, Transoma Medical, Arden Hills, MN).

A

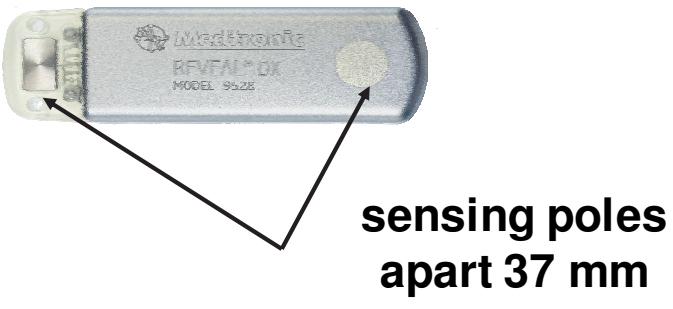

C

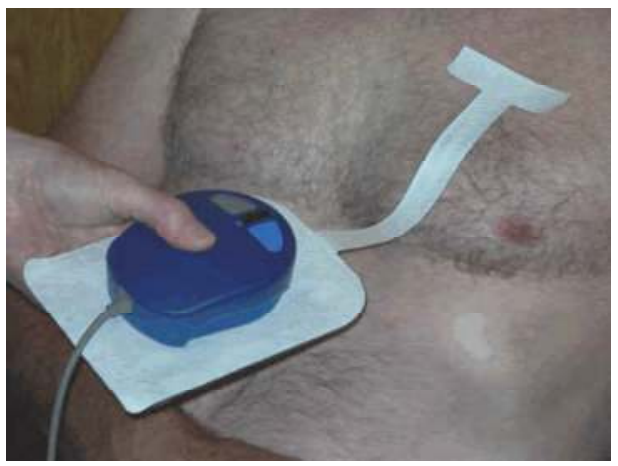

B

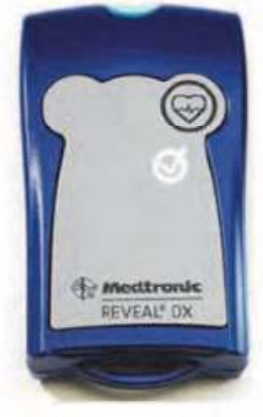

Fig. 1. A. Insertable cardiac monitor. B Reveal patient assistant in the pocket of the patient. C. Reveal Vector Check helps the physician to define the optimal implantation site based on the signal detection. D. Example of ECG recording with the Reveal Vector Check.

\subsection{Implantation technique and positions (anterior chest or left axillary)}

The ICM is easily inserted in the left chest using a local anesthetic with thorough asepsis in an operating room. A pocket is fashioned and the device is inserted with the electrodes towards the skin. The best implantation site is vertically to the right or left of the sternum between the fourth and the fifth intercostal spaces (Zellerhoff et al., 2000) (figure 2). With the latest version (Reveal DX) we can use the Reveal Vector Check to confirm the optimal implantation site based on signal detection. Sometimes an unusual site can be chosen, such left axillary implantation (figure 2). Miracapillo et al implanted 10 patients with an ICM in axillary position with success. The high R-wave amplitude obtained in this position was higher than with the standard position. The quality of the ECG recorder was always excellent and always allowed easy diagnosis interpretation (Miracapillo et al., 2010). This site of implantation might be very useful in younger patients for aesthetic reasons but also in obese patients to improve the amplitude of the R-wave recorded. 


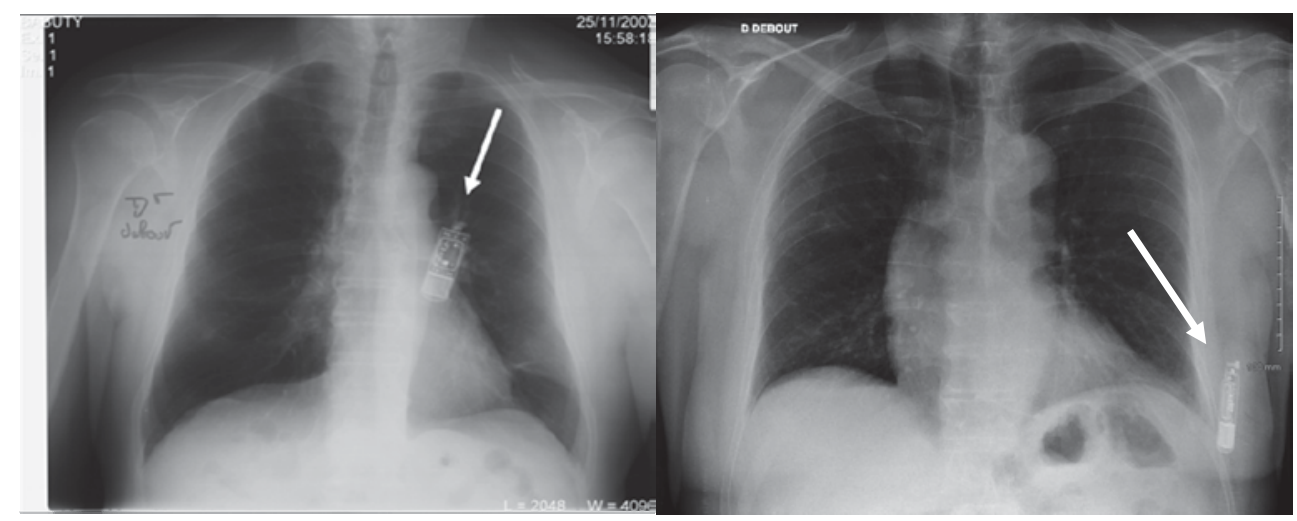

Fig. 2 Left. Anteroposterior chest radiography displays Reveal in a usual site. Right. Chest radiography shows Reveal inserted in a left axillary site in a young girl.

\subsection{Program parameters and control}

After implantation, the ICM is programmed. In the latest version of ICM, sensing and detection are automatically programmed (dynamic sensing threshold). Physicians can optimize the sensing of R-waves by adjusting the sensitivity parameters. Automatic ECG memory storage of episodes is activated by the physician (fast ventricular tachycardia, ventricular tachycardia, asystole, bradycardia) and the upper limits are defined. We can customize the detection criteria for each type of episode. Activation by the patient after syncope is possible with the Patient Assistant.

\subsection{Follow up}

Regular interrogation of the device is adviced to detect symptomatic or non-symptomatic arrhythmias or paroxysmal bradycardia. However for the past months it has been possible to control the ICM by telecardiology. This technology has several advantages, the control is permanent, the patient remains at home and the alerts are chosen by the cardiologist depending upon the clinical characteristics of the patient.

\subsection{False positive recording or limits of the method}

Five to $30 \%$ of patients failed to appropriately activate the device after syncope. That was a problem with the first generation of the device which has disappeared with the newer generations of the device. The second and third generations have the ability to record an event either automatically or by manual activation. The effectiveness of the automatic activation has been evaluated by Ermis et al. in 50 patients. The auto-activation mode was found to be more efficient in documenting arrhythmia episodes than the manual activation mode (48\% arrhythmia versus 6\%) (Ermis et al., 2003). One limit of the ICM is related to the transient loss of signal which generates a false flat baseline tracing (figure 3). A false ventricular pause can also be recorded with the latest generation of ICM characterized by an autodetection sensing of the QRS. The change in the $\mathrm{R}$ wave amplitude leads to their undersensing. Conversely, the oversensing of myopotential noises can lead to the detection of false ventricular tachycardia or fibrillation (Figure 4). The second limit of the ICM is the 
lack of contemporary recording of blood pressure values. Neurally-mediated syncopes are not always associated with bradycardia, but exclusive vasodepressor response is possible. These kinds of syncope cannot be diagnosed with the ICM nor the syncope linked to the modification or adjustment to the upright position. The exact nature of the syncope remains unknown in these conditions.

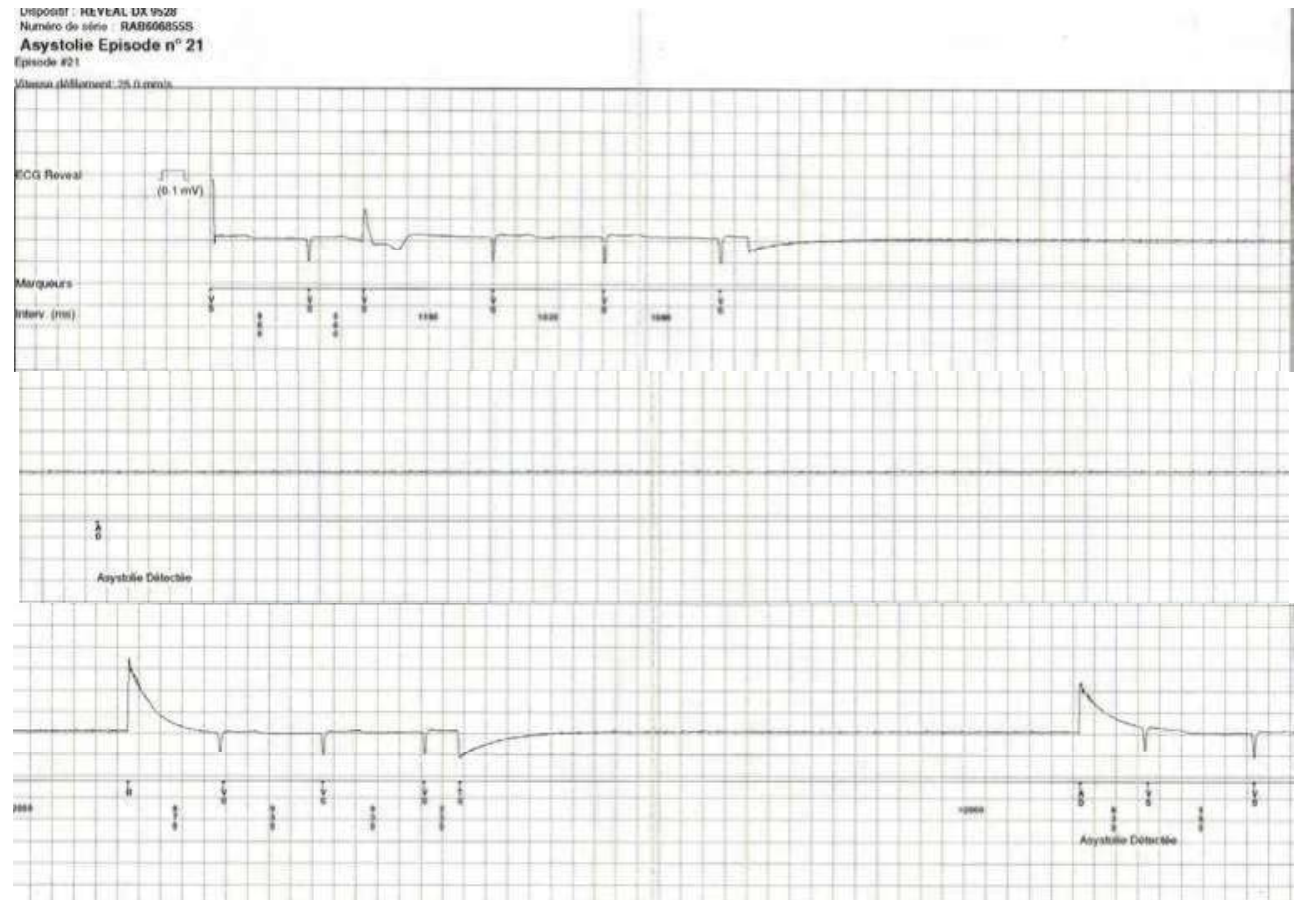

Fig. 3. Transient loss of signal which generates a false flat baseline tracing indicated as asystole in absence of presyncope or syncope.

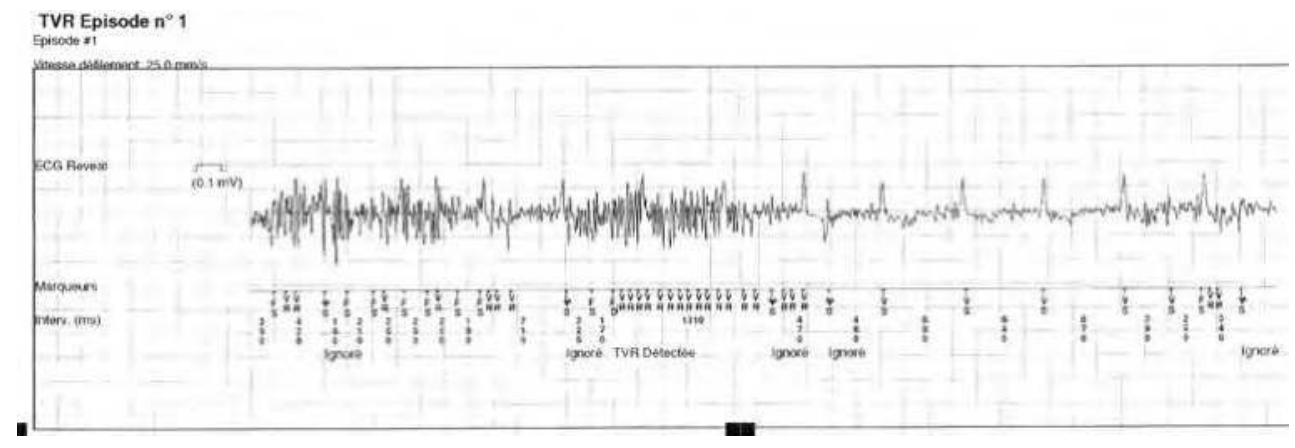

Fig. 4. Paroxysmal oversensing of $R$ waves confounded to myopotentiels (Reveal@ 9528). Fast ventricular tachycardia is the diagnosis retained by the device. 


\section{ICM implanted for recurrent syncopes}

\subsection{Results}

Initially, the implantation of the ICM was limited to patients with recurrent syncopes and thorough negative investigations including an electrophysiological study. After the implantation of the ICM about $50 \%$ of the patients complained of a new syncope (Krahn et al., 1999a; Nierop et al., 2000; Lombardi et al., 2005; Pierre et al., 2008; Entem et al., 2009). The syncope is correlated to a rhythmic event in about $50 \%$ of cases (Table 1 ). These results are confirmed in the largest registry published in 2011 (PICTURE registry): $38 \%$ of recruited patients complained of a recurrent syncope whose $59 \%$ have a cardiac aetiology (Edvardsson et al., 2011).

\begin{tabular}{|c|c|c|c|}
\hline Authors & $\begin{array}{c}\text { Patients } \\
\mathrm{n}\end{array}$ & $\begin{array}{c}\text { Syncope recurrence } \\
\mathrm{n}(\%)\end{array}$ & $\begin{array}{c}\text { Rhythmic event } \\
\mathrm{n}(\%)\end{array}$ \\
\hline Krahn 1999a & 85 & $58(68.2)$ & $21(42)$ \\
\hline Nierop 2000 & 35 & $14(40)$ & $8(57)$ \\
\hline Seidll 2000 & 133 & $83(62)$ & $32(39)$ \\
\hline Chettaoui 2002 & 32 & $15(46.8)$ & $10(71)$ \\
\hline Pierre 2008 & 95 & $43(45.2)$ & $27(62.8)$ \\
\hline Entem 2009 & 140 & $54(38.5)$ & $33(64.5)$ \\
\hline Edvardsson 2011 & 650 & $218(38)$ & $128(59)$ \\
\hline
\end{tabular}

Table 1. Frequency of recurrent syncope and rhythmic events in ICM patients

The most frequent recorded event is a sinus arrest or bradycardia (figure 5); a complete atrio-ventricular block is less frequent (figure 6) and tachycardia is rare (figures 7,8 ). Sinus bradycardia or sinus arrest account for the majority of the rhythmic events, and the duration of the events is widely variable (Table 2) (Chenet al., 2008). The ventricular pause can be severe, lasting up to 70 seconds (Babuty et al., 2001).

\begin{tabular}{|c|c|c|c|c|c|c|c|}
\hline Authors & Syncope & $\begin{array}{c}\text { Rhythmic } \\
\text { event }\end{array}$ & Bradycardia & AVB & SupraVT & VT & others \\
\hline $\begin{array}{c}\text { Krahn } \\
1999 \mathrm{a}\end{array}$ & 58 & 21 & 18 & $?$ & 3 & & \\
\hline $\begin{array}{c}\text { Nierop } \\
2000\end{array}$ & 14 & 14 & 4 & $?$ & 4 & & \\
\hline Seidl 2000 & 83 & 32 & 22 & $?$ & 6 & 3 & 1 \\
\hline Krahn 2001 & 30 & 11 & 10 & & 1 & & 3 \\
\hline $\begin{array}{c}\text { Chettaoui } \\
2002\end{array}$ & 15 & 21 & 2 & $?$ & 5 & 3 & \\
\hline $\begin{array}{c}\text { Brignole } \\
2005 \mathrm{~b}\end{array}$ & 22 & 17 & 3 & 14 & & & \\
\hline Pierre 2008 & 43 & 27 & 16 & 5 & 2 & 4 & \\
\hline Entem 2009 & 51 & 33 & 18 & 9 & 2 & 4 & \\
\hline
\end{tabular}

Table 2. Arrhythmic events documented by ICM 
However these results depend upon the patient's age: in older patients arrhythmic events are more frequent (3.1 higher probability of an arrhythmia) (Brignole et al., 2005a). In patients older than 65 years of age, complete atrio-ventricular block accounts for $53 \%$ of arrhythmia events.

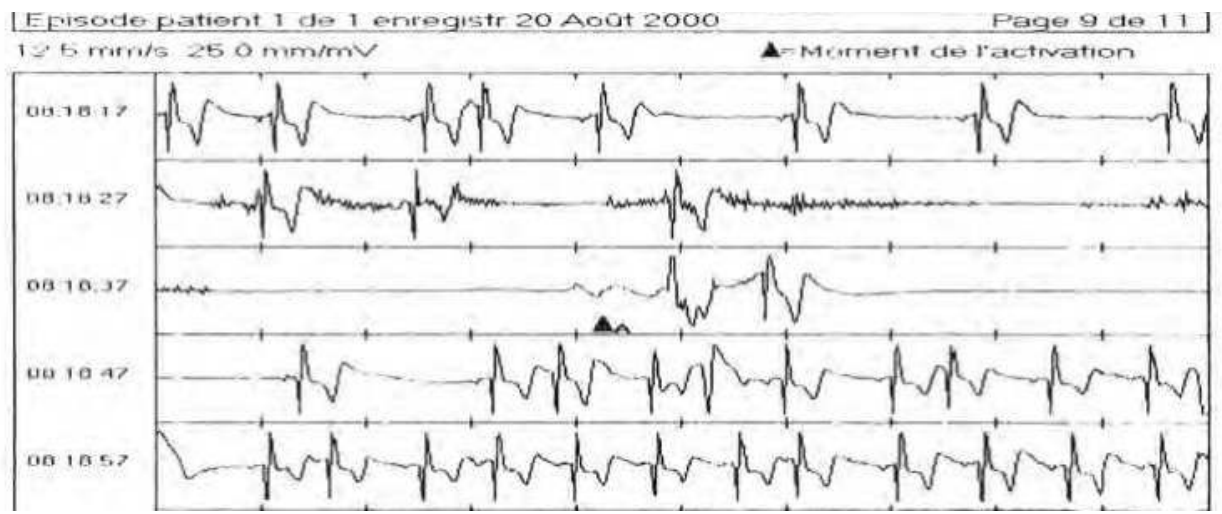

Fig. 5. Symptomatic sinus arrest during 9 seconds

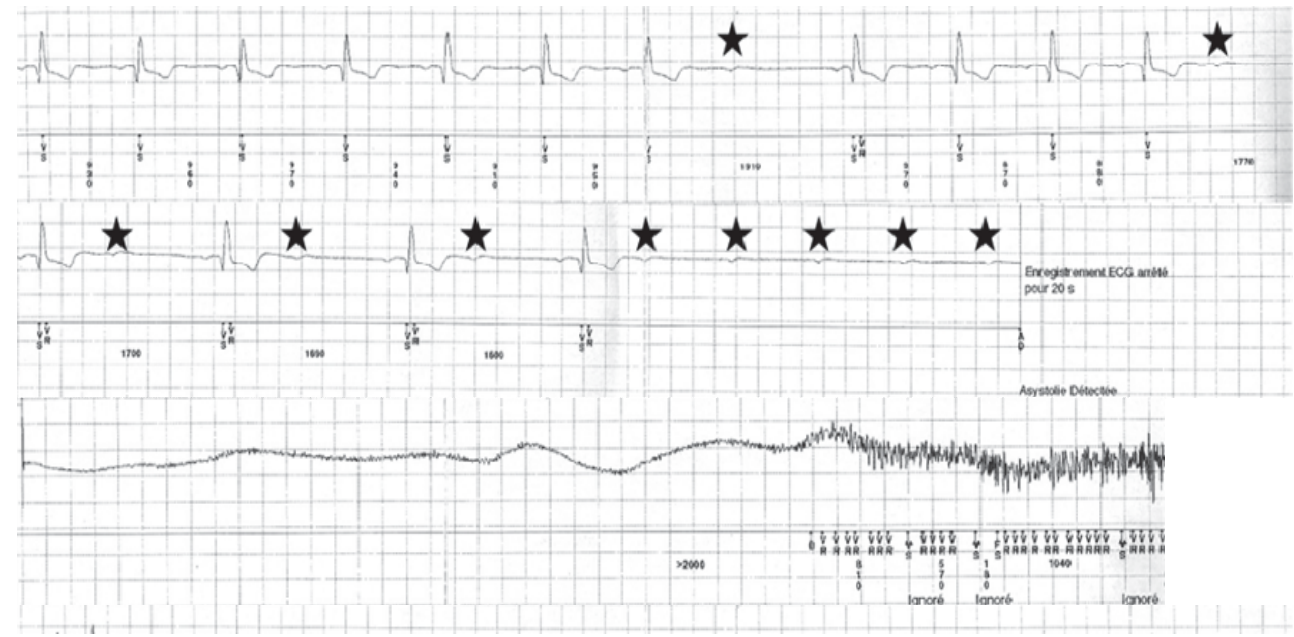

Fig. 6. Reveal's auto-activation captured a ventricular pause due to complete atrioventricular block. P waves are indicated by black stars.

The timeframe for recurrent symptoms shows that most events occur shortly after the implantation of the ICM: $31 \%$ within 30 days, 50\% within 2 months, $78 \%$ within 6 months and $93 \%$ within one year (Assar et al., 2003).

Syncope is more likely to be associated with an arrhythmia than presyncope. Krahn et al reported a higher incidence of arrhythmic events in the group of patients suffering from syncope $(64 \%)$ than in the group suffering from presyncope $(25 \%)$ (Krahn et al., 1999a, 2001a). 


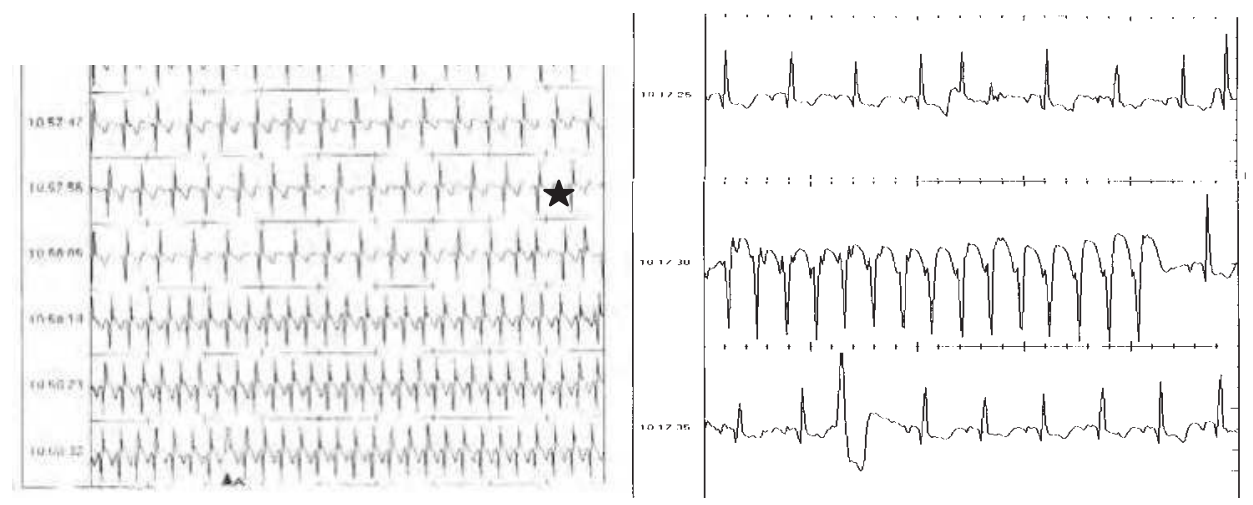

Fig. 7. Left. Symptomatic paroxysmal supraventricular tachycardia (black star). The electrophysiological demonstrated the atrioventricular nodal reentrant tachycardia. Right. Presyncope due to fast irregular tachycardia with wide QRS recorded in a patient without structural heart disease. During the electrophysiological study a right functional bundle branch block was induced by rapid atrial pacing. Atrial fibrillation was the final diagnosis and the patient was successfully treated with an antiarhythmic drug.

The International Study on Syncope of Uncertain Etiology (ISSUE) proposed a classification of spontaneous syncope documented by an implantable loop recorder (Brignole et al., 2005b) dependent on the mechanism of syncope (Table 3). The advantage of this classification is that of separating the syncope due to primary cardiac arrhythmia (Type 1C, type $4 \mathrm{~B}, 4 \mathrm{C}, 4 \mathrm{D}$ ) from neurally-mediated syncope (type 1A, 1B, type 2) and from unknown syncope (type 3). However this classification probably overestimated the number of neurally-mediated syncope because some sick sinus syndrome patients are included in type 2 .

\begin{tabular}{|c|c|}
\hline Arrhythmia & Mechanism \\
\hline $\begin{array}{l}\text { Type } 1 \text { Asystole (pause } \geq 3 \text { seconds) } \\
\text { Type } 1 \text { A Sinus arrest initiated by progressive bradycardia } \\
\text { or tachycardia }\end{array}$ & Neurally-mediated syncope \\
\hline $\begin{array}{l}\text { Type 1B Sinus bradycardia and AV block } \\
\text { Type } 1 \mathrm{C} \text { AV block sudden with concomitant increase in } \\
\text { sinus rate }\end{array}$ & $\begin{array}{l}\text { Neurally-mediated syncope } \\
\text { Primary cardiac arrhythmia }\end{array}$ \\
\hline $\begin{array}{l}\text { Type } 2 \text { Bradycardia } \\
\text { Type } 2 \mathrm{~A} \text { decrease of heart rate }>30 \% \\
\text { Type } 2 \mathrm{~B} \text { Heart rate }<40 \text { for } 10 \text { seconds }\end{array}$ & Neurally mediated syncope \\
\hline Type 3 No or slight rhythm variations & Unknown \\
\hline $\begin{array}{l}\text { Type } 4 \text { Tachycardia increase in heart rate }>30 \% \text { or }>120 / \mathrm{min} \\
\text { Type } 4 \text { A progressive sinus tachycardia } \\
\text { Type } 4 \mathrm{~B} \text { atrial fibrillation } \\
\text { Type } 4 \text { C supraventricular tachycardia } \\
\text { Type } 4 \text { D ventricular tachycardia }\end{array}$ & $\begin{array}{l}\text { Inadaptation to the upright } \\
\text { position } \\
\text { Primary cardiac arrhythmia } \\
\text { Primary cardiac arrhythmia } \\
\text { Primary cardiac arrhythmia }\end{array}$ \\
\hline
\end{tabular}

Table 3. The ISSUE classification of ECG-documented spontaneous syncope 


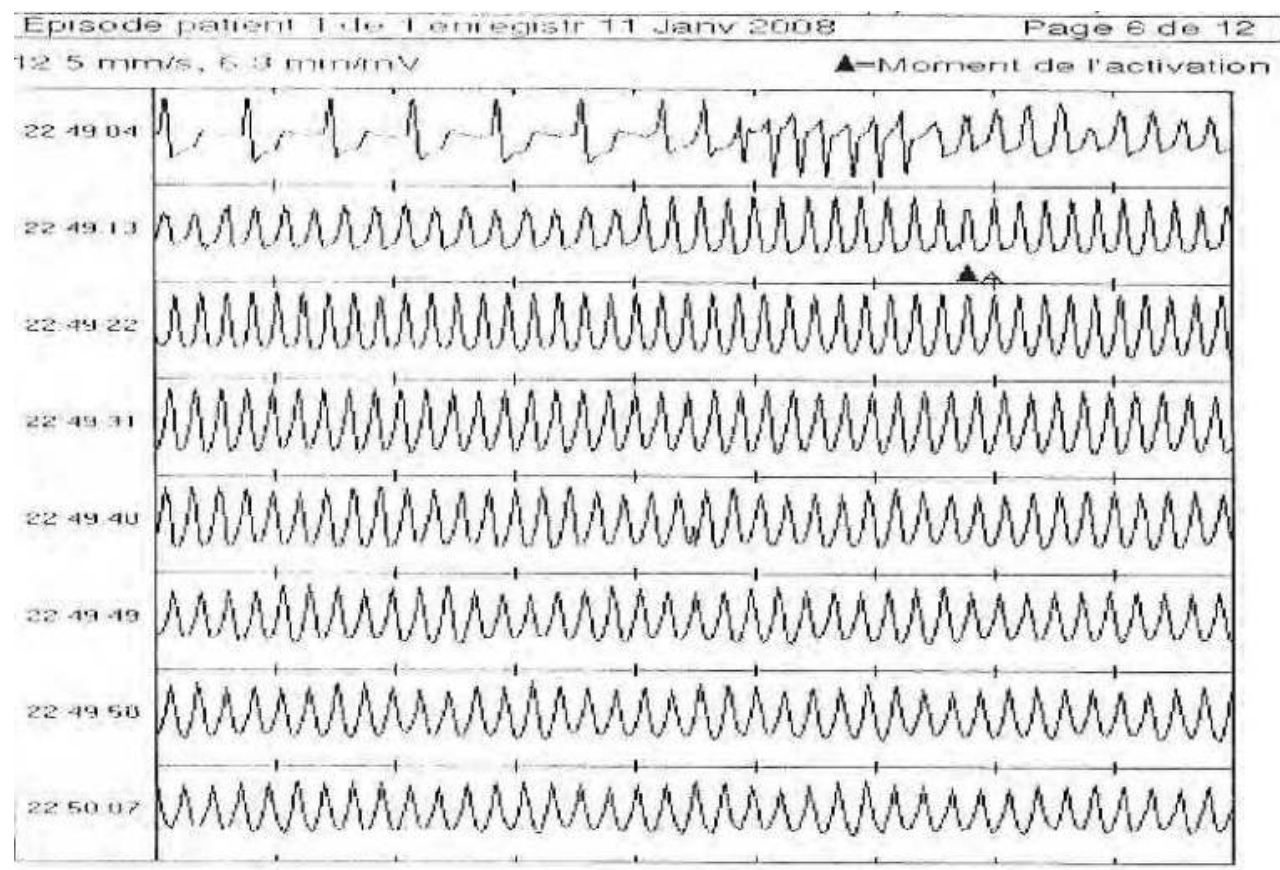

Fig. 8. Syncope due to fast ventricular tachycardia. Note the change of the QRS morphology at the beginning of the tachycardia.

\subsection{Influence of resting ECG and structural heart disease on results of ICM recordings} One generally analyzes with caution the patients suffering from syncope in the presence of abnormalities on resting ECG or in the presence of structural heart disease. The Task force defined some electrocardiographic conduction abnormalities suggesting an arrhythmic syncope: bifascicular block, QRS duration $\geq 0.12 \mathrm{~s}$, Mobitz I atrio-ventricular block, sinus bradycardia $<50 / \mathrm{min}$, or sinus pause $\geq 3 \mathrm{~s}$, non-sustained ventricular tachycardia, Preexcited QRS complexes and $\mathrm{T}$ wave abnormalities suggesting a primary electrical disease (Moya et al., 2009). However, some of these abnormalities are frequent and may not justify the implantation of a definitive pacemaker (Epstein et al., 2008) in the absence of infrahissian conduction disturbance or inducible arrhythmias recorded during the electrophysiological study. We recently reported in populations with a normal infrahissian conduction time that arrhythmic events were not more frequent in syncope patients with cardiac conduction abnormalities on resting ECG (Pierre et al., 2008) than in patients without them $(27.5 \%$ versus $28.7 \%$ ). Paroxysmal complete atrio-ventricular block remains rare in this selected population (13.7\% versus $1.5 \%)$. That was explained by the high frequency of symptomatic sinus arrest in the group of patients without cardiac conduction abnormalities on resting ECG and the very low frequency of complete atrio-ventricular block in bifascicular block defined by right bundle branch block and left axis deviation (Nierop et al., 2000; Brignole et al., 2001; Pierre et al., 2008).

However caution should be exercised in the presence of right bundle branch block associated with right axis deviation. In this case, the frequency of complete paroxysmal 
atrio-ventricular block is high (36\%) (Brignole et al., 2001). At the present time, patients with recurrent syncopes and right bundle branch block and right axis deviation are usually implanted with a permanent pace maker without prior implantation of the ICM (Epstein et al., 2008).

In the risk of stratification at the initial evaluation of syncope, the presence of cardiovascular disease and /or history of congestive heart failure are considered as major risk factors accounting for 3 points in EGSYS score and 1 point in OESIL score and these parameters are recognized as a predictive factor for cardiac arrhythmia in the latest guidelines for the diagnosis and the management of syncope (Task Force 2004; Moya et al., 2009). However, this conclusion cannot be applied to patients having recurrent syncopes and having undergone profound clinical cardiac investigation, especially when electrophysiological studies were unremarkable (Table 4). Several studies with the ICM demonstrated that cardiac arrhythmia was not correlated to the presence of structural heart disease (Mason et al., 2003; Solano et al., 2004; Pierre et al., 2008; Pezawas et al., 2008) in patients with recurrent syncopes. An arrhythmic event was documented more frequently in patients without structural heart disease than in patients with structural heart disease (33.7\% versus $9.5 \%)$ (Pierre et al., 2008).This significant difference was not observed in other studies (Mason et al., 2003; Pezawas et al., 2008). The aetiology of arrhythmia is controversial with regard to the presence or absence of structural heart disease: Solana et al reported a greater prevalence of primary cardiac arrhythmia (atrioventricular block and ventricular arrhythmia) in patients with structural heart disease than in patients without structural heart disease (sinus arrest primarily) (Solano et al., 2004). In contrast Pierre et al (Pierre et al., 2008) observed only one AV block and no ventricular arrhythmia in structural heart disease patients.

However, we must specify that in these studies, most patients with structural heart disease have normal or limited alteration of left ventricular ejection fraction (Menozzi et al., 2002). We should be cautious in patients with severe depressed left ventricular ejection fraction. In this population, the implantation of an automatic implantable defibrillator has to be discussed because the probability of severe ventricular arrhythmia is high (Epstein et al., 2008).

\begin{tabular}{|c|c|c|}
\hline Authors & $\begin{array}{c}\text { Cardiac disease } \\
\text { Documented arrhythmia } \\
(\%)\end{array}$ & $\begin{array}{c}\text { Without Cardiac disease } \\
\text { Documented arrhythmia } \\
(\%)\end{array}$ \\
\hline Mason 2003 & 31 & 29 \\
\hline Solano 2004 & 52 & 28 \\
\hline Pierre 2008 & 9.5 & 33.7 \\
\hline Pezawas 2008 & 45 & 51 \\
\hline
\end{tabular}

Table 4. Documented arrhythmia in patients with or without structural heart disease

\subsection{Interest of ICM in patients without structural heart disease and normal ECG}

Moya was the first author to report the results of ICM in patients suffering from recurrent syncopes with a normal physical examination and normal ECG without structural heart disease. These syncopes evoke a neuro-mediated mechanism. In this study (ISSUE), the rate of recurrence was high (34\%) and the major arrhythmic event documented in the ICM was prolonged asystole ( $>3$ secondes) regardless of the results of the tilt-testing (Moya et al., 
2001). Typically, a progressive sinus bradycardia precedes a ventricular asystole due to sinus arrest. Most of the asystolic pauses were very long at the time of the syncope (from 15 \pm 6 to $17 \pm 9$ seconds). These findings suggested that the syncope was neurally-mediated with a strong cardioinhibitory reflex. Deharo et al observed no correlation between the heart rhythm recorded by the ICM during a spontaneous vasovagal syncope and the heart rhythm recorded during the tilt testing or the ATP test (Deharo et al., 2006). ICM appears to better define the therapeutic strategy in these patients in accordance with heart rhythm contemporary to the syncope. The implantation of a definitive pacemaker in the group of patients with severe bradycardia proved its efficiency in preventing the recurrence of syncopes (only 0.05 episodes per patient per year) (Brignole et al., 2006). A multicenter prospective, double-blind randomized placebo-controlled study (ISSUE 3) is underway to assess the effectiveness of pacemaker therapy for syncopal asystolic pause (ISSUE 3, 2007).

\subsection{Value of asymptomatic arrhythmias in unexplained syncope}

The major interest of the ICM is to establish a closed correlation between symptoms and ECG. However long-term monitoring of patients with unexplained syncope with the ICM demonstrated frequent severe arrhythmic events (Krahn et al., 2004). Severe asymptomatic arrhythmia was documented in 15\% of patients in Krahn's study: sinus bradycardia, atrioventricular block, supraventricular tachycardia and ventricular tachycardia. Specific treatment resulted in the resolution of syncope. Asymptomatic arrhythmias are often clinically relevant, especially in syncope patients leading to pacemaker implantation in the case of bradycardia or ICD in case of ventricular tachycardia (Epstein et al., 2008). The guidelines of 2009 (Moya et al., 2009) retained the following diagnosis criteria in the absence of a clear correlation between symptoms and ECG monitoring: ECG monitoring is diagnostic when periods of Mobitz II or III degree AV block or ventricular pause $>3 \mathrm{~s}$ or rapid prolonged paroxysmal supraventricular tachycardia or ventricular tachycardia are detected. Caution should be considered with the possible exception of young trained persons, during sleep, medical patients, or rate-controlled atrial fibrillation.

\subsection{ICM in diagnosis and management of syncope: Theory and practice}

The first reports on ICM demonstrated the superiority of the ICM in terms of diagnosis over the conventional diagnostic testing. In the RAST trial including 60 recurrent syncope patients, a diagnosis was obtained in $43 \%$ of the patients randomized to ICM compared to $20 \%$ in the patients undergoing conventional diagnostic testing (Krahn et al., 2001). The Eastbourne Syncope Assessment Study recruited 201 patients randomized in the conventional investigation group $(n=98)$ and ICM group $(n=103)$. The superiority of the ICM in terms of diagnosis was evident: $42 \%$ versus $7 \%$ (hazard ratio for time to ECG diagnosis was 6.53). Moreover, the time to ECG directed therapy was quicker for the ICM group than for the conventional group (Farwell et al., 2006). The diagnosis performance of ICM depends on the duration of the follow-up and the segments of the patients. It varied from 27 to $50 \%$. ICM is especially powerful in older patients: a diagnosis was made for every 1.7 patients selected for ICM implantation in Brignole's study (Brignole et al., 2005a).

In the recommendations published in 2004 and revisited in 2009, the ICM implantation is recommended in two kinds of situations: firstly the ICM implantation appears early in patients with recurrent syncope of uncertain origin without high risk criteria and a high likelihood of recurrence of syncope within battery longevity of the ICM (class IB). Secondly 
the ICM implantation is recommended in high risk patients in whom a comprehensive evaluation did not demonstrate a cause of syncope or lead to a specific treatment (class IB). Generally in patients with a normal physical examination, normal ECG and without familial history of sudden cardiac death and structural heart disease and negative tilt testing, the implantation of ICM must be considered early in the presence of recurrent syncope. Selective use of an electrophysiological study and tilt testing must be discussed before implanting the ICM (Garcia-Civera et al., 2003). In the presence of cardiac disease or high risk criteria suggesting arrhythmic syncope as defined in the 2009 guidelines, it is recommended to implant ICM after performing an electrophysiological study and tilt testing (Moya et al., 2009). Several studies previously discussed in this chapter demonstrated the benefit of a strategy based on a relatively straightforward initial clinical evaluation: the early implantation of an ICM and a therapy delivered in accordance with the arrhythmic event documented during an episode of recurrent syncope (Brignole et al., 2005a, Pierre et al., 2008). The analysis of the presyncopal phase on the ICM restored ECG allows physicians to adapt and optimize the programming of the pacemaker when necessary (Brignole et al., 2007).

Table 5 summarized the recommendations of the implantation of the ICM in unexplained recurrent syncope. Vitale et al reported in a multicenter study a discrepancy between clinical practice and standardized indications for the ICM in patients with unexplained syncope (Vitale et al., 2010) whereas no clinical characteristics distinguished the patients receiving the ICM or not. Only $18 \%$ of patients received an ICM whereas $69 \%$ of patients had appropriate criteria for implantation of an ICM. In this study the ICM strategy allowed 8.7 higher likelihood of ECG diagnosis. This study underlines the underutilization of ICM in the diagnosis of syncope.

\begin{tabular}{|l|l|l|}
\hline \multicolumn{1}{|c|}{ Recommendations of ICM } & Class & Level \\
\hline $\begin{array}{l}\text { Early phase of evaluation in patients with } \\
\text { recurrent syncope of uncertain origin, absence } \\
\text { of high risk criteria and high likelihood of } \\
\text { recurrence within battery longevity of the } \\
\text { device }\end{array}$ & I & B \\
\hline $\begin{array}{l}\text { High risk patients in whom a comprehensive } \\
\text { evaluation did not demonstrate a cause of } \\
\text { syncope or lead to a specific treatment }\end{array}$ & I & B \\
\hline $\begin{array}{l}\text { Should be considered to assess the } \\
\text { contribution of bradycardia before embarking } \\
\text { on cardiac pacing in patients with suspected } \\
\text { or certain reflex syncope presenting with } \\
\text { frequent or traumatic syncopal episodes }\end{array}$ & IIa & B \\
\hline
\end{tabular}

Table 5. Recommendations of Implantable Cardiac monitor in accordance to the 2009 guidelines (Moya et al.; 2009)

\subsection{ICM in particular populations}

\subsubsection{ICM in children and young adults}

As we have previously noted, in children the ICM implantation can be safety implanted in the left axillary region for aesthetic reasons. Only a few experiences with the ICM in a 
paediatric setting have been published. Two studies reported the results in children suffering from recurrent syncopes. Results similar to those of adults are obtained in children. A high degree of symptom-rhythm correlation was established. In the Sreeram study (Sreeram et al., 2008), 15/33 patients had documented arrhythmic events which required specific therapy. In Babikar's study of the 15 patients who experienced symptom recurrence, $8(53 \%)$ had an arrhythmic event (polymorphic ventricular tachycardia $n=1$, supraventricular tachycardia $n=5$, sinus arrest $n=1$ and Mobitz II AV block $=1$ ) (Babikar et al., 2008). Al Dharhi et al reported $64 \%$ of diagnosis in 42 children implanted with ICM (Al Dharhi et al., 2009). Further studies are needed to confirm the benefit of ICM in the paediatric population and to confirm its tolerability.

\subsubsection{ICM in older patients}

Falls are a major health care concern in elderly patients. About $30 \%$ of people over 65 years fall once. The falls can unmask recurrent syncopes (Kenny et al., 2001; Amstrong et al., 2003). Some overlap between syncopes and falls has been recognized in the elderly population. Several parameters explain this confusion between falls and syncope: the interrogation, the amnesia for loss of consciousness and the difficulty to investigate these patients. Moreover falls are often unwitnessed, rendering the diagnosis of fall more difficult. The ICM is a simple tool that can be used early in the diagnostic strategy. In a small study reported by Amstrong about half of patients who activated their Reveal documented cardiac arrhythmias (bradycardia and ventricular tachycardia) (Amstrong et al., 2003). In the SAFE PACE study, a strong correlation between non-accidental falls and cardio-inhibitory carotid sinus hypersensitivity has been established (Kenny et al., 2001). The bradycardia induces hypotension which favours the instability of old patients leading to falls without loss of consciousness. In the absence of positive carotid sinus massage, the ICM can document bradycardia preceding the fall. The consequence for these patients is of great interest because the implantation of a definitive pacemaker dramatically reduced the injurious events.

\subsubsection{J wave syndromes and syncope}

Brugada syndrome and early repolarization are primary electrical diseases responsible for sudden death by ventricular fibrillation. Implantation of an ICD in secondary prevention is a class I recommendation (Epstein et al., 2008), but in primary prevention its implantation is controversial because a high incidence of complications linked to the ICD was observed in this young population (Sacher et al., 2006). Brugada syndrome and early repolarization are two electrocardiographic criteria that must suggest a diagnosis of cardiac arrhythmia in patients complaining from syncope (Moya et al., 2009). Nevertheless, the mechanism of syncope may be heterogeneous in these subgroups of patients and the differential between benign and malignant forms of syncope is not always very easy. The implantation of the ICM has been proposed by some authors especially when the characteristics of syncope were not convincing or the primary implantation of an ICD is refused by the patient. In the early repolarization syndrome the implantation of an ICD is only indicated in patients with documented ventricular arrhythmias. ICM can be used in other symptomatic patients.

\subsubsection{Epileptic patients, "convulsive syncope" and ICM}

Two problems remain unexplained in the epileptic population: the overlap between convulsive syncope and epilepsy and the high frequency of sudden death. Convulsive 
syncope is defined as cerebral anoxic seizure activity secondary to transient global impairment of blood flow, often difficult to differentiate from epilepsy. Sudden death is higher in the epileptic population than in the general population and frequently syncopes remain unexplained in the epileptic population despite adequate doses of anticonvulsant drugs (Tomson et al., 2008). Several hypotheses have been evoked amongst them the cardiovascular cause. Cardiologic investigations in this population reported an alternative diagnosis in $40 \%$ of cases (Zaidi et al., 2000a). Two types of clinical events have been demonstrated in this population. The first is a cardiac event linked to seizure, the second is a primary cardiac event. ICM can be useful to diagnose a cardiac event in these selected patients. Twenty patients with refractory epilepsy received an ICM in order to record heart rhythm during seizure (Rugg-gunn et al., 2004). 377 episodes were analyzed and bradycardia and sinus arrest occurred in 8 recorded events $(2.1 \%)$ but this represented four patients $(21 \%)$. These bradycardia are linked to temporal seizure (ictal bradycardia). The mechanism may be parasympathetic activation. We recently reported that syncopal bradycardia could be the first manifestation of epilepsy (Dinan et al., 2008). Videotelemetry monitoring with electroencephalography is the gold standard for diagnosing this particular form of epilepsy. The implantation of a pacemaker has been proposed to prevent death and disability (Zaidi et al., 2000a). The second mechanism is a neurocardiogenic syncope. In some patients, the neurocardiogenic syncope can result in convulsive syncope which can be difficult to distinguish from epilepsy. Despite a careful clinical investigation and laboratory tests including head upright tilt table testing, sometimes it is uncertain to conclude on the nature of the syncope. In this situation IMC is a power tool to display the cardiac rhythm during convulsive episodes (Kanjwal et al., 2009). Frequently a prolonged asystole or paroxysmal atrio-ventricular block was reported. The neurally-mediated mechanism is suspected in these patients because a slowing of heart rhythm was recorded before the asystole episode. The second argument is the inefficacity of the anti epileptic drugs and the disappearance of seizure after implantation of a dual chamber pacemaker in these patients. It is important to diagnose the cardiac origin of a convulsive syncope in order to avoid a long term anticonvulsant treatment which is expensive, inefficient and can cause serious morbidity.

\section{Cost-effectiveness of ICM in syncope patients}

Syncope is a symptom with an extensive differential diagnosis which can be roughly divided into cardiac syncope, neurally-mediated syncope, orthostatic hypotension and vascular steal syndromes (Moya et al., 2009). Consequently there is no single diagnostic test and more often, many laboratory tests (24 hours ambulatory ECG, tilt testing, electrophysiological study and echocardiography) are done, but their sensitivity and specificity are low. These laboratory tests significantly add to the overall cost, but their contribution to the diagnostic yield is low. About $40 \%$ of patients referred to the emergency department are hospitalized. Referred and hospitalized patients are known to generate a cost estimated between $\$ 3,000-25,000$, a mean cost of $\$ 5400$ per hospitalization in USA and $€ 3506$ in Italy (Moya et al.; 2009). The recording of the heart rhythm during the syncopal episode remains the only means to diagnosis an arrhythmic aetiology. Preliminary studies demonstrate the economic benefit of the ICM compared to the conventional strategy in reducing the cost of the diagnosis of syncope (Krahn et al.; 1999b; Zaidi et al.; 2000b; Ermis et al., 2003). The RAST study has the objective of comparing the cost of both strategies. In 
this study, the cost of a primary implantable loop recorder strategy is $26 \%$ less than that of conventional testing (Krahn et al., 2001b). Early application of ICM reduces the cost per patient ( $\$ 1,878$ versus 2,355 and per diagnosis $\$ 3,756$ versus 5,045$)$. In the EaSyAS study, the overall costs tended to be lower in the ICM group than in the conventional investigation group (Farwell et al., 2006).

\section{Others applications of ICM - Diagnosis of atrial fibrillation}

A new algorithm is proposed in the last version of ICM leading to a specific analysis of the atrial electrical activity and to improving the diagnosis of atrial fibrillation. This new device (Reveal® XT, Medtronic Inc, Minneapolis USA) has a good sensitivity (96.1\%) and specificity $(85.4 \%)$ for identifying patients with atrial fibrillation (Hindricks et al., 2010). Some teams already use these ICM after atrial fibrillation ablation in order to detect the recurrence of the arrhythmia. Such data offered a safer guide to continue or stop the anticoagulation and antiarrhythmic drugs (Pokushalov, et al., 2011). The application of this diagnosis method demonstrated in CARISMA study a high incidence of new-onset atrial fibrillation in patients recently hospitalized for myocardial infarction with left ventricular dysfunction (Jons, et al., 2011). The risk of major cardiovascular events in patients with newonset atrial fibrillation longer than 30 seconds was increased $(\mathrm{HR}=2.04)$ suggesting to treat these atrial fibrillation episodes. The implantation of the old version of the ICM has been already proposed in other domains than syncope. About $50 \%$ of strokes in young patients remain unexplained after non invasive investigations. One suspected diagnosis in this population is the occurrence of asymptomatic paroxysmal atrial fibrillation which can't be detected by the standard ECG or 24 hours ambulatory ECG. Some authors proposed to analyze the atrial vulnerability during an electrophysiological study but its specificity and sensibility are not defined in the prospective study. Dion et al tested the interest of the ICM (second generation Reveal Plus 9526) in young patients suffering from unexplained stroke. In this study the ICM did not display a high prevalence of atrial arrhythmias but the population was selected and the implantation was only performed three months after the stroke (Dion et al., 2010). Another limit of this study was the criteria to retain the diagnosis of atrial fibrillation which was an irregular tachycardia with narrow QRS complex. The application of the new algorithm to detect atrial arrhythmias in larger population of patients with unexplained stroke should be of great interest because the detection of symptomatic or not atrial fibrillation involves starting an oral anticoagulation. A new large randomized prospective study (CRYSTAL AF) is ongoing to evaluate the long term monitoring with the implantation of a subcutaneous cardiac monitor (Reveal XT) in patients with cryptogenic stroke (Sinha, AM.; 2010). Results are expected at the end of 2012. In the population of patients suffering from recurrent syncope or palpitations this new algorithm could also be useful to improve the diagnosis.

\section{Conclusion}

ICM or ILR is a new tool still underused in clinical practice. The longevity of the battery allows prolonged cardiac monitoring which is the most suitable investigation to correlate the symptom to an arrhythmic event. Recurrent syncope is the major indication of ICM implantation. Recurrent syncope may impair the survival and the quality of life of the patients, the capacity to work and the ability to drive. A long-term monitoring strategy with 
the ICM yields more diagnoses than with conventional testing. Early application of ICM is now recommended in patients with recurrent syncopes in order to diagnose the mechanism of the syncopes and to guide the effective therapy. New applications of the ICM are in development, especially in patients suffering from atrial fibrillation and in patients suffering from unexplained palpitations.

\section{References}

Al Dharhi, K.; Potts, J.; Chiu, C. ; Hamilton, R. \& Sanatani, S. (2009). Are implantable loop recorders useful in detecting arrhythmias in children with unexplained syncope ? PACE, Vol 32, No., (November 2009), pp1422-1427.

Armstrong, L.; Lawson, .J; Kamper, A.; Newton, J. \& Kenny, RA. (2003).The use of implantable loop recorder in the investigation of unexplained syncope in older people. Age and Ageing, Vol.32, No.2, (March 2003), pp. 185-188.

Assar, M.; Krahn, A.; Klein, G.; Yee, R. \& Skanes, A. (2003). Optimal duration of monitoring in patients with unexplained syncope. American Journal of Cardiology, Vol.92, (2003), pp.1231-123.

Babikar, A.; Hynes, B.; Ward, N.; Oslizok, P.; Walsh, K. \& Keane, D. (2008). A retrospective study of the clinical experience of the implantable loop recorder in a pediatric setting. International Journal of Clinical Practice, Vol.62, No.10, (October 2008), pp.1520-1525.

Babuty, D.; Petitjean, F.; Fauchier, L. \& Cosnay, P. (2001). Amazing sinus cardiac arrest. Journal of Cardiovascular Electrophysiology, Vol.12, No. 12, (December 2001), pp.1431.

Brignole, M.; Menozzi, C.; Moya, A.; Garcia-Civera, R.; Mont, L.; Alvarez, M.; Errazquin, F.; Beinas, J.; Bottoni, N. \& Donateo, P. (2001). Mechanism of syncope in patients with bundle branch block and negative electrophysiological test. Circulation, Vol.104, No.17, (October 2001), pp. 2045-2050.

Brignole, M. ; Menozzi, C. ; Maggi, R. ; Solano, A. ; Donateo, P. ; Bottoni, N. ; Lolli, G.; Quarteri, F.; Croci, F. ; Oddone, D. \& Puggioni, L. (2005a). The usage and diagnosis yield of the implantable loop-recorder in detection of the mechanism of syncope and in guiding effective antiarrhythmic therapy in older people. Europace, Vol.7, No.3, (May 2005), pp.273-279.

Brignole, M.; Moya, A.; Menozzi, C.; Garcia-Civera, R. \& Sutton, R. (2005b). Proposed electrocardiographic classification of spontaneous syncope documented by an implantable loop recorder. Europace, Vol.7, No.1, (January 2005), pp. 14-18.

Brignole, M.; Sutton, R.; Menozzi, C.; Garcia-Civera, R.; Moya, A.; Wieling, W.; Andresen, D.; Benditt, DG. \& Vardas, P. (2006). Early application of implantable loop recorder allows effective specific therapy in patients with recurrent suspected neurally mediated syncope. European Heart Journal, Vol.27, No.9, (May 2006), pp. 1085-1092.

Brignole, M.; Sutton, R.; Wieling, W.; Lu, SN.; Erickson, MK.; Markowitz, T.; Grovale, N.; Ammirati, F. \& Benditt, DG. (2007). Analysis of rhythm variation during spontaneous cardioinhibitory neurally-mediated syncope. Implications for RDR pacing optimization: an ISSUE 2 substudy. Europace, Vol.9, No.5, (May 2007), pp. 305-311, ISSN

Chettaoui, R.; Kouakam, C.; Klug, D.; Marquie, C. \& Lacroix D. (2002). Value of an implantable ECG monitor for the etiological diagnosis of syncope and recurrent 
unexplained syncopal attacks. Archives des Maladies du Coeur et des vaisseaux, Vol.95, No.1, (January 2002), pp. 29-36, ISSN

Chen, LY.; Benditt, DG. \& Shen WK. (2008). Management of syncope in adults: an update. Mayo Clinic Proceeding, Vol.83, No.11, (November 2008), pp. 1280-1293.

Entem, FR.; Enriquez, SG.; Cobo, M.; Expositi, V.; Liano, M.; Ruiz, M.; Ollala, J. \& OteroFernadez, M. (2009). Utility of implantable loop recorders for diagnosing unexplained syncope in clinical practice. Clinical Cardiolology, Vol.32, No.1,(January 2009), pp. 28-31.

Dinan, A.; de Toffol, B.; Pallix, M.; Breard, G. \& Babuty, D. (2008). Cardiac arrest: it's all in the head. Lancet, Vol.371, No. 9622, (April 2008), pp.1476.

Deharo, JC.; Jego, C.; Lanteaume, A. \& Djiane P. (2006). An implantable loop recorder study of highly symptomatic vasovagal patients. Journal of American College of Cardiology, Vol.47, (2006), pp.587-593, ISSN

Dion, F.; Saudeau, D.; Bonnaud, I.; Friocourt, P.; Bonneau, A.; Poret, P.; Giraudeau, B.; Régina, S.; Fauchier, L. \& Babuty D. (2010). Unexpected low prevalence of atrial fibrillation in cryptogenic ischemic stroke: a prospective study. Journal of Interventional Cardiac Electrophysiology, Vol.28, No.2, (August 2010), pp. 101-107, ISSN

Edvardsson, N.; Frykman, V.; van Mechelen, R.; Mitro, P.; Mohii-Oskarson, A.; Pasquié, JL.; Ramanna, H.; Schwertfeger, F.; Ventura, R.; Vulgaraki, D.; Garutti, C.; Stolt, P. \& Linker, N. (2011). Use of an implantable loop recorder to increase the diagnosis yield in unexplained syncope: results from the PICTURE registry. Europace, Vol.13, No.3, (February 2011), pp. 262-269., ISSN

Epstein, AE. (2008). ACC/AHA/HRS 2008 guidelines for device-bases therapy of cardiac rhythm abnormalities. Journal of American College of Cardiology, Vol.51, No.21, (May 2008), pp. 1-62.

Ermis, C.; Zhu, AX.; Pham, S.; Li, JM.; Guerrero, M.; Vrudney, A. ; Hiltner, L. ; Lu, F.; Sakaguchi, KG. \& Benditt, DG. Comparison of automatic and patient-activated arrhythmia recordings by implantable loop recorder in the evaluation of syncope. American Journal of Cardiology, Vol.92, No.7, (October 2003), pp. 815-819.

Farwell, DJ.; Freemantle, N. \& Sulke, N. (2006). The clinical impact of implantable loop recorders in patients with syncope. European Heart Journal, Vol.27, No.3, (February 2006), pp. 351-356.

Garcia-Civera, R. ; Ruiz-Granell, R.; Morell-Cabedo, S. ; Sanjuan-Manez, R.; Perez-Alcala, F.; Plancha, E.; Navarro, A. ; Botella, S. \& LLacer, A. (2003). Selective use of diagnostic tests in patients with syncope of unknown cause. Journal of American College of Cardiology, Vol.41, No.5, (March 2003), pp.787-790.

Hindricks, G.; Pokushalov, E.; Urban, L.; Taborsky, M.; Kuck, KH.; Lebedev, D.; Rieger, G. \& Pürerfellner, H. (2010). Performance of a new leadless implantable cardiac monitor in detecting and quantifying atrial fibrillation. Results of the EXPECT trial. Circulation Arrhythmia Electrophysiology, Vol.3, No.2,(April 2010), pp. 141-147, DOI: 10.1161/CIRCEP.109.877852.

Jons, C.; Jacobsen, U.; Joergensen, R.; Olsen, N. ; Dixen, U. ; Johannessen, A. ; Huikuri, H. ; Messier, M.; McNitt, S. \& Thomsen, P. (2011). The incidence and prognostic significance of new-onset atrial fibrillation in patients with acute myocardial 
infarction and left systolic fysfunction: a CRISMA study. Heart Rhythm, Vol.8, No. 3, (March 2011), pp342-348.

Kanjwal, K.; Karabin, B.; Kanjwal,Y. \& Grubb, B. (2009). Differentiation of convulsive syncope from epilepsy with an implantable loop recorder. International Journal of Medical Sciences, Vol.6, No.6, ( September 2009), pp.296-300.

Kapoor, WN.; Karpf, M.; Wieand, S.; Peterson, JR. \& Levey, GS. (1983). A prospective evaluation and follow-up of patients with syncope. New England Journal of Medecine, Vol.309, No.4, (July 1983), pp. 197-204.

Kenny, A.; Richardson, D.; Steen, N.; Bexton R.; Shaw, F \& Bond, J. (2001). Carotid sinus syndrome: a modifiable risk factor for non accidental falls in older adults (SAFE PACE). Journal of American College of Cardiology, Vol.38, No.5, (November 2001), pp. 1491-1496, ISSN 0735-1097/01.

Krahn, AD.; Klein, GJ.; Yee, R.; Takle-Newhouse, T. \& Norris, C. (1999a). Use of an extended monitoring strategy in patients with problematic syncope. Circulation, Vol.99, No.3, (January 1999), pp. 406-410.

Krahn, AD.; Klein, GJ.; Yee, R. \& Manda, V. (1999b). The high cost of syncope: cost implications of a new insertable loop recorder in the investigation of recurrent syncope. American Heart Journal, Vol.137, No.5, (May 1999), pp. 870-877.

Krahn, AD.; Klein, GJ.; Yee, . \& Skanes, AC. (2001a). Predictive value of presyncope in patients monitored for assessment of syncope. American Heart Journal, Vol.141, No., (2001), pp.817-821.

Krahn, AD.; Klein, G.; Yee, R. \& Skanes, AC. (2001b). Randomized assessment of syncope Trial (RAST). Circulation, Vol.104, No.1, (July 2001), pp.46-51.

Krahn, AD.; Klein, GJ.; Yee, R. \& Skanes, AC. (2004). Detection of asymptomatic arrhythmias in unexplained syncope. American Heart Journal, Vol.148, No.2, (August 2004), pp.326-332.

Lombardi, F. ; Calasso, E. ; Mascioli, G. ; Marangoni, E. ; Donato, A. ; Rossi, S. ;Pala, M.; Foti, F.\& Lunati, M. (2005). Utility of implantable loop recorder (Reveal Plus) in the diagnosis of unexplained syncope. Europace, Vol.7, No.1, (January 2005), pp.19-24.

Mason, P.; Wood, MA.; Reese, DB.; Lobban, JH.; Mitchell, MA. \& DiMarco, JP. (2003). Usefulness of implantable loop recorders in office-based practice for evaluation of syncope in patients with or without structural heart disease. American Journal of Cardiology, Vol.92, No.9, (November 2003), pp.1127-1129.

Menozzi, C.; Brignole, M.; Garcia-Civera, R.; Moya, A.; Botto, G.; Tercedor, L.; Migliorini, R. \& Navarro, X. (2002). Mechanism of syncope in patients with heart disease and negative electrophysiological test. Circulation, Vol.105, No.23, (June 2002), pp.27412745.

Miracapillo, G.; Costoli, A.; Addonisio, L.; Gemignani, L.; Manfredini, E.; Corbucci, G.; Severi, S. \& Barold S. (2010). Left axillary implantation of loop recorder. PACE, Vol.33, No.8, (August 2010), pp.999-1002, DOI: 10.1111/j.1540-8159.2010.02764.x

Moya, A. ; Brignole, M.; Menozzi, C. ; Garci-Civera, R. ; Tognarini, S. ; Mont, L. ; Botto, G.; Giada, F. \& Cornacchia, D. (2001). Mechanism of syncope in patients with isolated syncope and in patients with tilt-positive syncope. Circulation, Vol.104, No.11, (September 2001), pp.1261-1267.

Moya, A.; Sutton, R. ; Ammirati, F. ; Blanc, JJ. ; Brignole, M. ; Dahm, JB. ; Deharo, JC. ; Gajek, J. ; Gjesdal, K. ; Krahn, A.; Massin, M.; Pepi, M.; Pezawas, T.; Granell, RR.; Sarasin, 
F.; Ungar, A.; va Dijk, J, Walma, E. \& Wieling, W. (2009). Guidelines for the diagnosis and management of syncope (Version 2009). European Heart Journal, Vol.30, No.21, (November 2009), pp.2631-2671, DOI: 10.1093/eurheartj/ehp298.

Nierop, PR.; Van Mechelen, R.; Van Elsächer, R.; Luitjen, RHM. \& Elhendy, A. (2000). Heart rhythm during syncope and presyncope: results of implantable loop recorder. PACE, Vol.23, No.10, (October 2000), pp.1532-1538.

Paruchuri, V.; Adhaduk, M.; Garikipati, NV.; Steinberg, JS. \& Mittal S. (2011). Clinical utility of a novel wireless implantable loop recorder in the evaluation of patients with unexplained syncope. Heart Rhythm, (February 2011) (Epub ahead of print)

Pierre, B.; Fauchier, L.; Breard, G.; Marie, O.; Poret, Ph. \& Babuty, D. (2008). Implantable loop recorder for recurrent syncope : influence of cardiac conduction abnormalities showing up on resting electrocardiogram and of underlying cardiac disease on follow-up developments. Europace, Vol.10, No.4, (April 2008), pp. 477-481.

Pezawas,T.; Stix, G.; Kastner, J.; Schneider, B.; Wolzt, M. \& Schmidinger, H. (2008). Implantable loop recorder in unexplained syncope: classification, mechanism, transient loss of consciousness and role of major depressive disorder in patients with and without structural heart disease. Heart, Vol.94, No.4, (April 2008), pp.1-7.

Pokushalov, E.; Romanov, A.; Corbucci, G.; Artyomenko, S.; Turov, A.; Shirokova, N. \& Karaskov, A. (2011). Ablation of paroxysmal and persistent atrial fibrillation: 1-year follow up through continuous subcutaneous monitoring. Journal of Cardiovascular Electrophysiology, in press.

Rugg-Gunn, F.; Simister, R.; Squirell, M.; Holdright, D. \& Duncan, J. (2004). Cardiac arrhythmias in focal epilepsy: a prospective long term study. Lancet, Vol.364, No.9452, (December 2004), pp.2212-2219.

Sacher, F.; Probst, V.; Iesaka, Y.; Jacon, P.; Laborderie, J.; Mizon-Gérard, F.; Mabo, P.; Reuter, S.; Lamaison, D.; Takahashi, Y.; O’Neill, M.; Garrigue, S.; Pierre, B.; Jaïs, P.; Pasquié, JL. ; Hocini, M.; Salvador-Mazenq, M.; Nogami, A.; Amiel, A.; Defaye, P.; Bordachar, P.; Boveda, S.; Maury, P.; Klug, D.; Babuty, D.; Haïssaguerre, M.; Mansourati, J.; Clémenty, J. \& Le Marec, H. (2006). Outcome after implantation of a cardioverter-Defibrillator in patients with Brugada syndrome. A multicenter study. Circulation, Vol.114, No.22 (November 2006), pp.2317-2324, DIO: 10.1161/CIRCULATIONAHA.106.628537.

Siedl, K.; Rameken, M.; Breunung, S.; Senges, J.; Jung, W.; Andresen, D.; va Toor, A.; Krahn, A. \& Klein, G. Diagnostic assessment of recurrent unexplained syncope with a new subcutaneously implantable recorder. Europace, Vol.2, No.3, (July 2000), pp.256-262.

Sinha, AM.; Diener, HC.. Morillo, C.; Sanna, T.; Berstein, R.; Di Lazzaro, V.; Passman, R.; Beckers, F. \& Brachmann, J. (2010). Cryptogenic stroke and underlying atrial fibrillation (CRYSTAL AF): Design and rationale). American Heart Journal, Vol.160, No.1, (July 2010), pp. 36-41.

Sivakumaran, S.; Krahn, A.; Klein, GJ.; Finan, J.; Yee, R.; Renner, S. \& Skanes, AC. (2003). A prospective randomized comparison of loop recorders versus Holter monitoring in patients with syncope and presyncope. American Journal of Medecine, Vol.115, No.1, (July 2003), pp.1-5.

Solano, A.; Menozzi, C.; Maggi, R.; Donateo, P.; Bottoni, N.; Lolli, G.; Tomasi, C.; Crosi, F.; Oddone, D.; Puggioni, F. \& Brignole, M. (2004). Incidence, diagnostic yield and safety of the implantable loop-recorder to detect the mechanism of syncope in 
patients with or without structural heart disease. European Heart Journal, Vol.25, No.13, (July 2004), pp. 1116-1119.

Soteriades, E.; Evans, JC.; Larson, MG.; Chen, MH.; Chen, L.; Benjamin,EJ. \& Levy, D. (2002). Incidence and prognosis of syncope. New England Journal of Medecine, Vol.347, No.12, (September 2002), pp.878-885.

Sreeram, N.; Gass, M.; Apitz, C.; Ziemer, G.; Hofbeck, M.; Emmel, M.; et al. (2008). The diagnostic yield from implantable loop recorders in children and young adults. Clinical Research Cardioliology, Vol.97, No.5, (May 2008), pp.327-333.

Strickberger A, Benson W, Biaggioni I, Callans D, Cohen M, Ellenbogen K, et al AHA/ ACCF Scientific statement on the evaluation of syncope. Circulation, Vol.113, No.17, (January 2006), pp.316-327.

Task force Guidelines on Management (Diagnosis and treatment) of syncope-Update 2004. The task force on syncope, European society of cardiology. European Heart Journal, Vol. 25, No.25, (November 2004), pp. 2054-2072.

Tomson, T.; Nashef, L. \& Ryvlin, P. (2008). Sudden unexpected death in epilepsy : current knowledge and future directions. Lancet Neurology, Vol.7, No.11, (November 2008), pp.1021-1031.

The steering Committee of the ISSUE 3 study. (2007). International study on syncope of uncertain etiology 3 (ISSUE 3): pacemaker therapy for patients with asystolic neurally-mediated syncope: rationale and study design. Europace, Vol.9, No.1 (January 2007), pp. 25-30.

Vitale, E.; Ungar, A. ; Maggi, R. ; Francese, M. ; Lunati, M. ; Colaceci, R. ; Del Rosso, A. ; Castro, A. ; Santini, M. ; Giuli, S .; Belgini, L.; Casagranda, I. \& Brignole, M. (2010). Discrepancy between clinical practice and standardized indications for an implantable loop recorder in patients with unexplained syncope. Europace, Vol.12, No10.,(October 2010), pp.1475-1479. DIO:10.1093/europace/euq302.

Zaidi, A.; Clough, P.; Cooper, P.; Scheepers, B. \& Fitzpatrick AP. (2000a). Misdiagnosis of epilepsy: many seizure-like attacks have a cardiovascular cause. Journal of American College of Cardiology, Vol.36, No.1, (July 2000), pp. 181-184, ISSN 075-1097/00.

Zaidi, AM. \& Fitzpatrick, AP. (2000b). Investigation of syncope: increasing the yield and reducing the cost. European Heart Journal, Vol.21, No.11, (June 2000), pp. 877-880.

Zellerhoff, C.; Himmrich, E.; Nebeling, D.; Przibille, O.; Nowak, B. \& Liebrich, A. (2000). How can we identify the best implantation site for an ECG event recorder? PACE, Vol.23, No.10, (October 2000), pp. 1545-1549. 


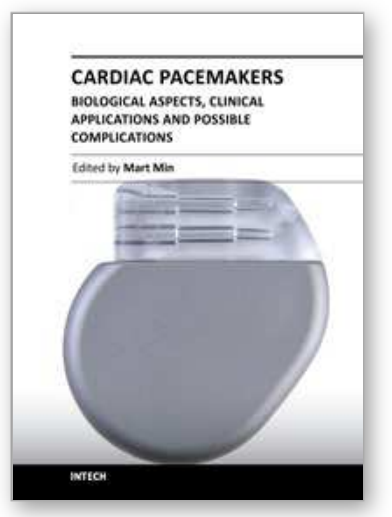

\section{Cardiac Pacemakers - Biological Aspects, Clinical Applications and Possible Complications}

Edited by Prof. Mart Min

ISBN 978-953-307-639-3

Hard cover, 194 pages

Publisher InTech

Published online 06, September, 2011

Published in print edition September, 2011

Clinical usage of artificial pacing dates back to 1958, when the battery powered cardiac pacemakers became available. Modern implantable pacemakers are the complicated electronic devices operating 10 years continuously without battery exchange. Though the development of devices is not a primary topic of the book, certain efforts towards developing of biologic pacemakers through tissue engineering and studying of cell synchronization are discussed. The main attention is paid to implementations of pacemakers in different medical situations oriented towards widening the clinical indications for implanting the cardiac pacemakers. New methods and devices in cardiac resynchronization therapy (CRT) have received particular attention. Placing of pacing electrodes has been treated soundly. Furthermore, emerging of complexities and complications in new clinical situations and other safety problems have been discussed thoroughly. The authors have derived the used information from their own clinical practice and experiences of their medical colleagues. These and other pragmatic features can be acknowledged as the most valuable asset of the book.

\section{How to reference}

In order to correctly reference this scholarly work, feel free to copy and paste the following:

Dominique Babuty, Bertrand Pierre, Nicolas Clémenty, Bénédicte Lallemand, Olivier Marie and Laurent Fauchier (2011). Implantable Loop Recorder in Clinical Practice, Cardiac Pacemakers - Biological Aspects, Clinical Applications and Possible Complications, Prof. Mart Min (Ed.), ISBN: 978-953-307-639-3, InTech, Available from: http://www.intechopen.com/books/cardiac-pacemakers-biological-aspects-clinical-applicationsand-possible-complications/implantable-loop-recorder-in-clinical-practice1

\section{INTECH}

open science | open minds

\section{InTech Europe}

University Campus STeP Ri

Slavka Krautzeka 83/A

51000 Rijeka, Croatia

Phone: +385 (51) 770447

Fax: +385 (51) 686166

www.intechopen.com

\section{InTech China}

Unit 405, Office Block, Hotel Equatorial Shanghai

No.65, Yan An Road (West), Shanghai, 200040, China 中国上海市延安西路65号上海国际贵都大饭店办公楼 405 单元

Phone: +86-21-62489820

Fax: +86-21-62489821 
(C) 2011 The Author(s). Licensee IntechOpen. This chapter is distributed under the terms of the Creative Commons Attribution-NonCommercialShareAlike-3.0 License, which permits use, distribution and reproduction for non-commercial purposes, provided the original is properly cited and derivative works building on this content are distributed under the same license. 